\title{
Resuscitative endovascular balloon occlusion of the aorta may contribute to improved survival
}

\author{
Makoto Aoki ${ }^{1 *} \mathbb{D}$, Toshikazu Abe ${ }^{2,3}$, Shuichi Hagiwara ${ }^{4}$, Daizoh Saitoh ${ }^{5}$ and Kiyohiro Oshima ${ }^{1}$
}

\begin{abstract}
Background: Resuscitative endovascular balloon occlusion of the aorta (REBOA) is an increasingly used trauma resuscitation procedure, however, there are no reports of whether or not the survival of patients treated with REBOA increases over time.

Methods: This retrospective cohort study from a nationwide trauma registry in Japan was conducted between 2004 and 2015. Patients treated with REBOA were divided into three calendar year periods: early-period (20042007), mid-period (2008-2011), and late-period (2012-2015). The primary outcome of in-hospital survival was compared between the periods (early-period: reference) using mixed effects logistic regression analysis after adjustment for characteristics, trauma severity, and therapeutic choices.
\end{abstract}

Results: Of 236,698 trauma patients, 633 patients treated with REBOA were analyzed. Distribution of the patients across periods was as follows: early-period (91), mid-period (276), and late-period (266). In-hospital survival was 39, 49 , and $60 \%$ in the early-period, mid-period, and late-period, respectively. In regression modeling, the late-period $(\mathrm{OR}=2.976,95 \% \mathrm{Cl}=1.615-5.482)$ was associated with improved in-hospital survival compared to the early-period, however, the mid-period $(\mathrm{OR}=1.614,95 \% \mathrm{Cl}=0.898-2.904)$ was not associated with improved survival.

Conclusions: Survival of patients treated with REBOA during the late-period improved compared with survival during the early-period, after adjustment for characteristics, trauma severity, and therapeutic choices. REBOA may be one of the important factors related to progression of modern trauma treatment.

Keywords: Resuscitative endovascular balloon occlusion of the aorta (REBOA), Japan, Logistic models, Mortality trend, Trauma

\section{Background}

Resuscitative endovascular balloon occlusion of the aorta (REBOA) is a worldwide topic in modern trauma care. The first use of REBOA was reported more than 50 years ago [1]. The clinical application of REBOA originated from treatments for abdominal aneurysm rupture [2] and obstetric complications [3], and has recently

\footnotetext{
* Correspondence: aokimakoto@gunma-u.ac.jp

'Department of Emergency Medicine, Gunma University Graduate School of Medicine, Maebashi, Japan

Full list of author information is available at the end of the article
}

extended into trauma medicine $[4,5]$. In Japan, REBOA was approved by the Japanese Ministry of Health in 2000 and initially used as an alternative method to resuscitative open aortic cross-clamping [6] in trauma medicine, after which it became widely recognized.

Nationwide multi-institutional studies reported that REBOA for severe trauma patients was associated with higher mortality $[7,8]$, ranging from 36 to $76 \%[7-9]$. Through the development of advances in trauma practices, survival of severely injured patients has improved in Japan [10-12], however, there is no evidence that

(c) The Author(s). 2020 Open Access This article is licensed under a Creative Commons Attribution 4.0 International License, which permits use, sharing, adaptation, distribution and reproduction in any medium or format, as long as you give appropriate credit to the original author(s) and the source, provide a link to the Creative Commons licence, and indicate if changes were made. The images or other third party material in this article are included in the article's Creative Commons licence, unless indicated otherwise in a credit line to the material. If material is not included in the article's Creative Commons licence and your intended use is not permitted by statutory regulation or exceeds the permitted use, you will need to obtain permission directly from the copyright holder. To view a copy of this licence, visit http://creativecommons.org/licenses/by/4.0/ The Creative Commons Public Domain Dedication waiver (http://creativecommons.org/publicdomain/zero/1.0/) applies to the data made available in this article, unless otherwise stated in a credit line to the data. 
long-term survival of REBOA patients has improved. Therefore, this study aimed to investigate whether survival of patients treated with REBOA improved during a 12-year period.

\section{Methods}

\section{Study design}

This retrospective cohort study was conducted to evaluate whether survival of severe trauma patients treated with REBOA was improved during the time period of 2004 to 2015 or not, using recorded data from the Japan Trauma Data Bank (JTDB). The study was approved by the medical ethics committee of the Gunma University Hospital.

\section{Data collection}

Data were obtained from the JTDB, a nationwide trauma registry established in 2003 by the Japanese Association for the Surgery of Trauma and the Japanese Association for Acute Medicine to improve and ensure the quality of trauma care in Japan. During the study period, a total of 260 hospitals including $95 \%$ of tertiary emergency medical centers in Japan participated in the JTDB. The JTDB collects 92 data elements that are related to patient and hospital information such as patient demographics, injury type, transport type, prehospital treatment, prehospital vital signs, vital signs at hospital arrival, trauma scores such as abbreviated injury scale (AIS) score for head, chest, abdomen and pelvis, injury severity score (ISS), revised trauma score (RTS), probability of survival (Ps), in-hospital procedures, blood transfusion quantity within $24 \mathrm{~h}$ from arrival at hospital, in-hospital mortality. However, detailed information about the use of REBOA, such as indication, occlusion time, and placement zone are not recorded in the JTDB.

\section{Patient selection}

Patients treated with REBOA were included in the study. Study patients were defined after the following exclusion criteria: dead on arrival, an AIS score $=6$ (i.e., unsurvivable injury) for any region, an unclear AIS score for any region, aortic cross clamping, cardiopulmonary resuscitation (CPR), and missing data on patient survival. The existence of aortic cross clamping and CPR were thought to be indicative of resuscitation and strongly related to outcome, therefore, patients with those procedures were excluded. Study patients were analyzed according to three calendar year periods: early-period (2004-2007), mid-period (2008-2011), and late-period (2012-2015).

\section{Study endpoints}

The primary outcome of this study was in-hospital mortality, and the secondary outcome was survival during the first 2 days because REBOA was generally used as a resuscitation procedure in acute trauma phase.

\section{Statistical analyses}

Data collected in this study contained missing values, especially for prehospital vital signs. There is no established statistical method to identify the reasons for missing values, however, the occurrence of missing values in this study was considered to be strongly related to the other observed variables from a clinical perspective, and the reason for missing values was assumed to be random. Therefore, missing data on the collected variables were completed by multivariate imputation by chained equations, and 20 datasets were produced.

After pooling all the imputed datasets into one dataset, continuous variables were expressed as medians (interquartile range $[\mathrm{IQR}])$, and categorical variables were presented as counts and percentages. Comparisons of continuous variables between three calendar year periods were performed using the Kruskal-Wallis test. Categorical variables were expressed as counts and percentages, and comparisons of each categorical variable between periods were performed using the Chi-Square test and/or Fisher's exact test. Predictive values were integrated across the imputed datasets, based on Rubin's rule [13].

To assess whether in-hospital survival was improved over time, univariate analyses and mixed-effects logistic regression analyses were performed. Calendar year periods were included as a categorical variable, with the earlyperiod as the reference period. We carefully selected confounders on the assumption that none was directly affected by the calendar year periods. Issues with variable multicollinearity were assessed by variance inflation factor (VIF) analysis with the tolerance value set at $<2$. The covariates included age, gender, injury type, transport type, prehospital vital signs (i.e., prehospital systolic blood pressure, prehospital heart rate and prehospital respiratory rate), vital signs at hospital arrival (i.e., systolic blood pressure, heart rate, respiratory rate and Glasgow Coma Scale [GCS] value), AIS scores for head, chest, abdomen, and pelvis, and focused assessment with sonography for trauma (FAST). In addition, mixed-effects logistic regression analysis was performed with adjustment for patient demographics (such as age and gender), trauma severity (such as injury type, prehospital vital signs, vital signs at hospital arrival, and AIS score), therapeutic choices (such as transporter type and FAST), and calendar year on outcome. In the analyses, patient demographics, trauma severity, therapeutic choices, and calendar year were considered fixed effect variables, and the hospital's unique identifier was considered a random effect variable. This model simultaneously adjusted for both patient level and within-hospital level confounding. Regarding in-hospital survival, we performed sub-group analyses (severe traumatic brain injury (AIS for head $\geqq 3$ ), severe abdominal injury (AIS for abdomen $\geqq 3$ ) and severe pelvic injury (AIS for pelvis $\geqq 3)$ ). 
Next, we performed analyses with a model in which calendar year was incorporated as a continuous variable, and a mixed-effects logistic regression model was used for in-hospital survival. Association between calendar year and outcome was plotted by a generalized additive mixed model, which was fit using the residual maximum likelihood method to account for possible nonlinear relationships between calendar year and outcome. The model was also adjusted for patient demographics such as age and gender, trauma severity such as injury type, prehospital vital signs, vital signs at hospital arrival, AIS score, therapeutic choices such as transporter type and FAST, and the hospital's unique identifier. Calendar year was incorporated into the models as a continuous variable and a smoothing term. We performed sensitivity analysis by univariate linear regression to find trends between in-hospital survival and calendar year. We performed additional analysis to evaluate whether survival of the patients who underwent CPR and treated REBOA were improved.

Second, to assess whether the use of REBOA was associated with improvement of in-hospital survival among severely injured patients, we set matched patients without REBOA by using propensity score matching (PSM). A logistic regression analysis was performed to estimate a PS for the prediction of REBOA+ or REBOA- based on available predictors. Clinically important confounders were included in the calculation of the PS. The variables of PSM were age, sex, calendar year periods, injury type, transport type, prehospital vital signs, vital signs at hospital arrival, AIS code for head, chest, abdomen and pelvis, and abdominal focused assessment sonography for trauma (FAST), initial treatments and blood transfusion quantity within first $24 \mathrm{~h}$. The PSM extracted 1:1 matched pairs of patients using a caliper with 0.2 with REBOA + or REBOA- based on the averaged PS. The absolute standardized difference of variables for the estimation of PS was used to assess the match balance, whereby an absolute standardized difference $>0.1$ represented a meaningful imbalance. In the PS-matched cohorts, univariate analyses were performed to evaluate outcome between REBOA+ and REBOA-

Statistical significance was defined as a two-sided $p$ value $<0.05$ or was assessed by a $95 \%$ confidence interval (CI) in all statistical analyses. Statistical analyses were performed by the IBM SPSS Statistics version 23.0 (SPSS Inc., Chicago, Illinois, USA) and $\mathrm{R}$ software (version 3.5.2; R Foundation for Statistical computing, Vienna, Austria). Multiple imputation was performed with $\mathrm{R}$ package "mice", mixed-effects logistic regression analysis modeling was performed with R package "lme4", generalized additive mixed modeling was performed with $\mathrm{R}$ package "mgcv" and propensity score matching was performed with R package "Matching".

\section{Results}

A total of 236,698 patients were registered in the JTDB from 1 January 2004 to 31 December 2015 (Fig. 1), of whom 1238 were treated with REBOA. From these 1238 patients, 604 were excluded for the following reasons: dead on arrival (214), AIS score $=6$ (13), unclear AIS score (9), aortic cross clamping (97), CPR (236), and missing data in primary outcome (35). Therefore, a total of 633 patients treated with REBOA were analyzed.

Characteristics of the multiply imputed dataset are shown in Table 1, and the distribution of naïve data and proportions of missing values are shown in Supplemental Table 1. The distribution of patients across the periods was as follows: early-period, $n=91$; mid-period, $n=276$; and late-period, $n=266$. The median age of patients was $54(34-71)$ years, and the majority of patients were male (66\%). The most common injury type was traffic accident (60\%). Regarding transport type, physician treatment tended to be performed in the lateperiod compared to the early-period $(p<0.001)$. While, there was no difference in prehospital intravenous fluids administration $(p=0.137)$. There was significant difference in prehospital systolic blood pressure $(p=0.046)$, however, there were no significant differences in other prehospital vital signs and vital signs at hospital arrival. There were no significant differences in trauma scores (AIS for head, chest, abdomen and pelvis, ISS, RTS and Ps). The percentages of patients who had a positive FAST assessment were significantly higher in the earlyperiod $(p=0.029)$. Regarding treatment types, the percentage of patients who had a celiotomy was significantly higher in the early-period $(p=0.026)$. There was no significant difference in blood transfusion quantity $(p=0.218)$ across the periods.

From comparison of outcomes between the calendar year periods, in-hospital survival was 39,49 , and $60 \%$ in the early-period, mid-period, and late-period, respectively (Table 2). Survival during the first 2 days was 43 , 57 , and $71 \%$ in these groups, respectively. Subgroups' and matched patients' outcome were shown in Supplemental Table 2. Outcome assessed by mixed effects logistic regression modeling demonstrated that the lateperiod $($ Odds ratio $(\mathrm{OR})=2.976,95 \% \mathrm{CI}=1.615-5.482$ ) was associated with improved in-hospital survival compared to the early-period, however, the mid-period $(\mathrm{OR}=1.614,95 \% \mathrm{CI}=0.898-2.904)$ was not associated with improved survival (Fig. 2). When calendar year was incorporated into a generalized additive mixed model as a continuous variable, it was significantly associated with increased in-hospital survival $(p<0.001)$ (Fig. 3). This result revealed an increasing monotonic association between calendar year and in-hospital survival. Sensitivity analysis demonstrated a monotonic trend between inhospital survival and calendar-year, and the annual 


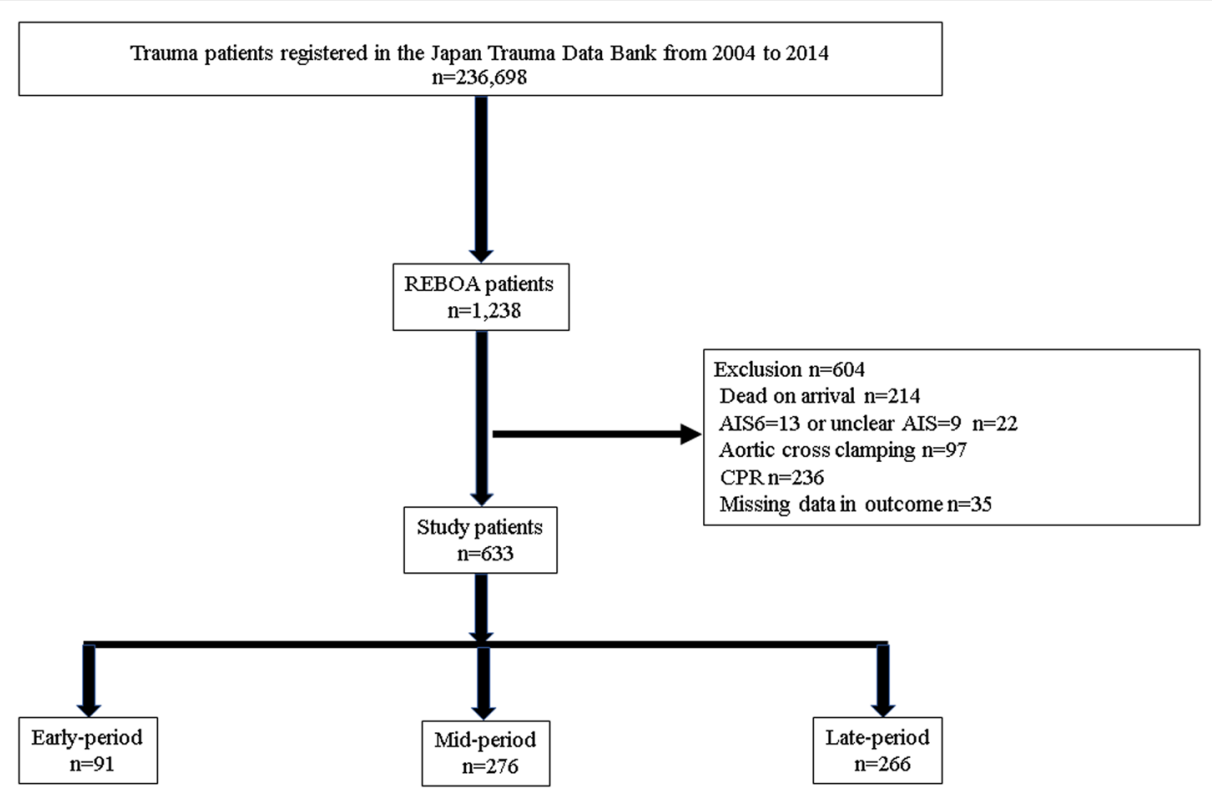

Fig. 1 Flow chart of patients included in this study. REBOA, resuscitative endovascular balloon occlusion of the aorta; AIS, abbreviated injury scale; $\mathrm{CPR}$, cardiopulmonary resuscitation

increase in survival percentage was 3.0\% (Supplemental Table 3). On the other hands, the survival of the patient who had CPR and were treated by REBOA was not improved (Supplemental Table 4).

\section{Discussion}

This study from JTDB demonstrated that survival of patients who were treated with REBOA during the lateperiod (2012-2015) was increased compared with survival during the early-period (2004-2007). While clinical severity and indication for REBOA chronologically changed, the survival of REBOA patients was improved in the late-period (2012-2015) after adjustment for confounders.

\section{Comparison with previous study}

The previous report [10] from JTDB pointed out the problem that mortality of severely injured patients who needed definitive interventions was not decreased until 2011. Subsequently, reports since 2010 have showed that mortality of severely injured patients with $\mathrm{Ps}<0.5$ or ISS $>16$ has decreased $[11,12]$. The present study adds information about the progress of trauma care in Japan. For example, the survival of severely injured patients who were treated with REBOA was still not improved into the mid-period (2008-2011 years), however, it was achieved in the late-period (2012-2015 years). To our knowledge, this is the first report that investigated the outcome of patients who were treated with REBOA for a long period of time.
We cannot simply compare the REBOA patients' survival with other reports. However, even if we considered trauma severity of patients, indication for REBOA use, and reported time periods, the survival of patients in this study during the late-period was high compared with that in previous reports, including reports from other countries (Supplemental Table 5) [4-9, 14-28]. Considering the outcome of patients who were treated with REBOA, their survival naturally varied by how REBOA was used and by the initiation timing of REBOA [16]. Therefore, after differentiating our analyzed patients from those who were dead on arrival, had unsurvivable injury or had underwent CPR (Supplemental Table 4), we could detect positive intervention effect of REBOA in study's patients. This feature of our study could be one reason for the comparably high survival rate.

Interpretation and implications.

We could not conclude with certainty that REBOA was the only factor that contributed to improved survival because the survival of all trauma patients in Japan has increased during the time period of our study. To assess the association between REBOA and improved survival, we set the matched patients' cohorts without REBOA, and we confirmed the matched patients' outcome was not improved (Supplemental Table 2 and 6). While, other factors also contributed to improve the survival rate and we could control factors such as demographics and trauma severity to prevent indication bias, and we used mixed effects regression analysis to control biases that could result from differences in how REBOA was used in each hospital. Because the increased use of 
Table 1 Characteristics of multiply imputed dataset

\begin{tabular}{|c|c|c|c|c|}
\hline Subgroups & $\begin{array}{l}\text { Early-period } \\
(2004-2007) \\
(n=91)\end{array}$ & $\begin{array}{l}\text { Mid-period } \\
(2008-2011) \\
(n=276)\end{array}$ & $\begin{array}{l}\text { Late-period } \\
(2012-2015) \\
(n=266)\end{array}$ & $P$-Value \\
\hline Age & $49(30-68)$ & $54(32-7)$ & $57(36-72)$ & 0.136 \\
\hline Sex, Male (\%) & $64(70)$ & $178(65)$ & $177(67)$ & 0.587 \\
\hline Injury Type & & & & 0.987 \\
\hline TA & $56(61)$ & $162(59)$ & $162(61)$ & \\
\hline Fall & $24(26)$ & $72(26)$ & $69(26)$ & \\
\hline Other blunt & $5(5.7)$ & $21(7.6)$ & $16(6.0)$ & \\
\hline Penetrate & $6(6.9)$ & $21(7.6)$ & $19(7.2)$ & \\
\hline Transport type & & & & 0.001 \\
\hline Ambulance & $83(91)$ & $223(81)$ & $186(70)$ & \\
\hline Dr-car & $2(2.2)$ & $10(3.6)$ & $26(9.8)$ & \\
\hline Helicopter & $6(6.8)$ & $41(15)$ & $53(20)$ & \\
\hline Other & $0(0)$ & $2(0.7)$ & $1(0.4)$ & \\
\hline \multicolumn{5}{|l|}{ Prehospital treatment } \\
\hline Intravenous fluids & $5(5.5)$ & $32(11.6)$ & $35(13.2)$ & 0.137 \\
\hline \multicolumn{5}{|l|}{ Prehospital vital signs } \\
\hline sBP & $98(78-118)$ & $94(78-118)$ & $104(80-129)$ & 0.046 \\
\hline $\mathrm{HR}$ & $96(79-120)$ & $96(80-120)$ & $100(82-120)$ & 0.331 \\
\hline RR & $24(18-30)$ & $24(21-30)$ & $24(20-30)$ & 0.064 \\
\hline \multicolumn{5}{|l|}{ Vital signs at hospital arrival } \\
\hline $\mathrm{sBP}, \mathrm{mmHg}$ & $80(40-104)$ & $80(62-105)$ & $80(62-111)$ & 0.452 \\
\hline$H R$ & $108(93-126)$ & $105(85-124)$ & $109(85-128)$ & 0.602 \\
\hline $\mathrm{RR}$ & $24(20-30)$ & $27(20-30)$ & $25(20-30)$ & 0.183 \\
\hline GCS & $9(3-14)$ & $11(6-14)$ & $12(6-14)$ & 0.617 \\
\hline \multicolumn{5}{|l|}{ AIS, n, median (95\% Cl) } \\
\hline Head & $41,3(3-5)$ & $105,4(3-5)$ & $100,4(3-5)$ & 0.784 \\
\hline Chest & $52,4(3-4)$ & $162,4(3-4)$ & $166,4(3-4)$ & 0.281 \\
\hline Abdomen & $71,4(3-4)$ & $204,3(3-4)$ & $175,4(3-4)$ & 0.381 \\
\hline Pelvis & $51,3(2-5)$ & $171,4(3-5)$ & $175,4(3-5)$ & 0.529 \\
\hline ISS & $33(20-45)$ & $34(20-45)$ & $34(22-45)$ & 0.610 \\
\hline RTS & $5.4(3.6-6.9)$ & $5.9(4.2-7.1)$ & $6.0(4.4-7.1)$ & 0.125 \\
\hline Ps & $55(13-92)$ & $63(23-89)$ & $58(23-89)$ & 0.734 \\
\hline Abdominal FAST & & & & 0.029 \\
\hline Positive & $59(65)$ & $171(62)$ & $132(50)$ & \\
\hline Negative & $29(32)$ & $97(35)$ & $124(47)$ & \\
\hline Not conducted & $3(3.3)$ & $8(3.0)$ & $10(3.8)$ & \\
\hline \multicolumn{5}{|l|}{ Initial Treatment } \\
\hline Thoracotomy & $3(3.3)$ & $16(5.8)$ & $13(4.9)$ & 0.632 \\
\hline Celiotomy & $52(57)$ & $143(52)$ & $114(43)$ & 0.026 \\
\hline TAE & $25(28)$ & $69(25)$ & $89(34)$ & 0.090 \\
\hline Blood Transfusion Quantity & $24(16-40)$ & $26(16-44)$ & $22(14-38)$ & 0.218 \\
\hline
\end{tabular}

$T A$ traffic accident, sBP systolic blood pressure, HR heart rate, RR respiratory rate, GCS Glasgow Coma Scale, AIS abbreviated injury scale, ISS injury severity score, RTS revised trauma score, Ps provability of survival, FAST focused assessment with sonography for trauma, TAE transcatheter arterial embolization 
Table 2 Outcome of REBOA patients according to year groups

\begin{tabular}{lllll}
\hline Outcome & $2004-2007$ & $2008-2011$ & $2012-2015$ & P-Value \\
\hline In-hospital survival & $35(39)$ & $134(49)$ & $160(60)$ & 0.001 \\
Survival during the first 2 days & $39(43)$ & $156(57)$ & $190(71)$ & $<0.001$
\end{tabular}

Missing numbers, Survival during the first 2 days $=2$

$R E B O A$ resuscitative endovascular balloon occlusion of the aorta

prehospital treatment was considered to be another confounder related to increased survival [29], we controlled it as a covariate. Early recognition of severely injured patients who need REBOA is important. After excluding the dead on arrival and CPR patients in this study, vital signs were more mild as they were expected and the patient could have underwent REBOA placement before becoming hemodynamically collapsed. The consideration to use REBOA as early as possible was an important indication bias in this study, therefore, we controlled for prehospital vital signs and therapeutic choices such as prehospital treatments and FAST. Early recognition and intervention for severely injured patients could contribute to increased survival of REBOA patients, however, we could not conclude from this study whether it was early recognition of severely injured patients or early intervention that improved survival. Matsumura, et al. reported from a Japanese REBOA registry that all prehospital REBOA patients survived [30]. We did not have information about prehospital REBOA use from the JTDB, but we believe that use of REBOA at the prehospital stage may be useful $[14,30]$. On the other hands, earlier recognition and earlier placement of REBOA may imply that REBOA was placed in the patients who do not clinically need REBOA.

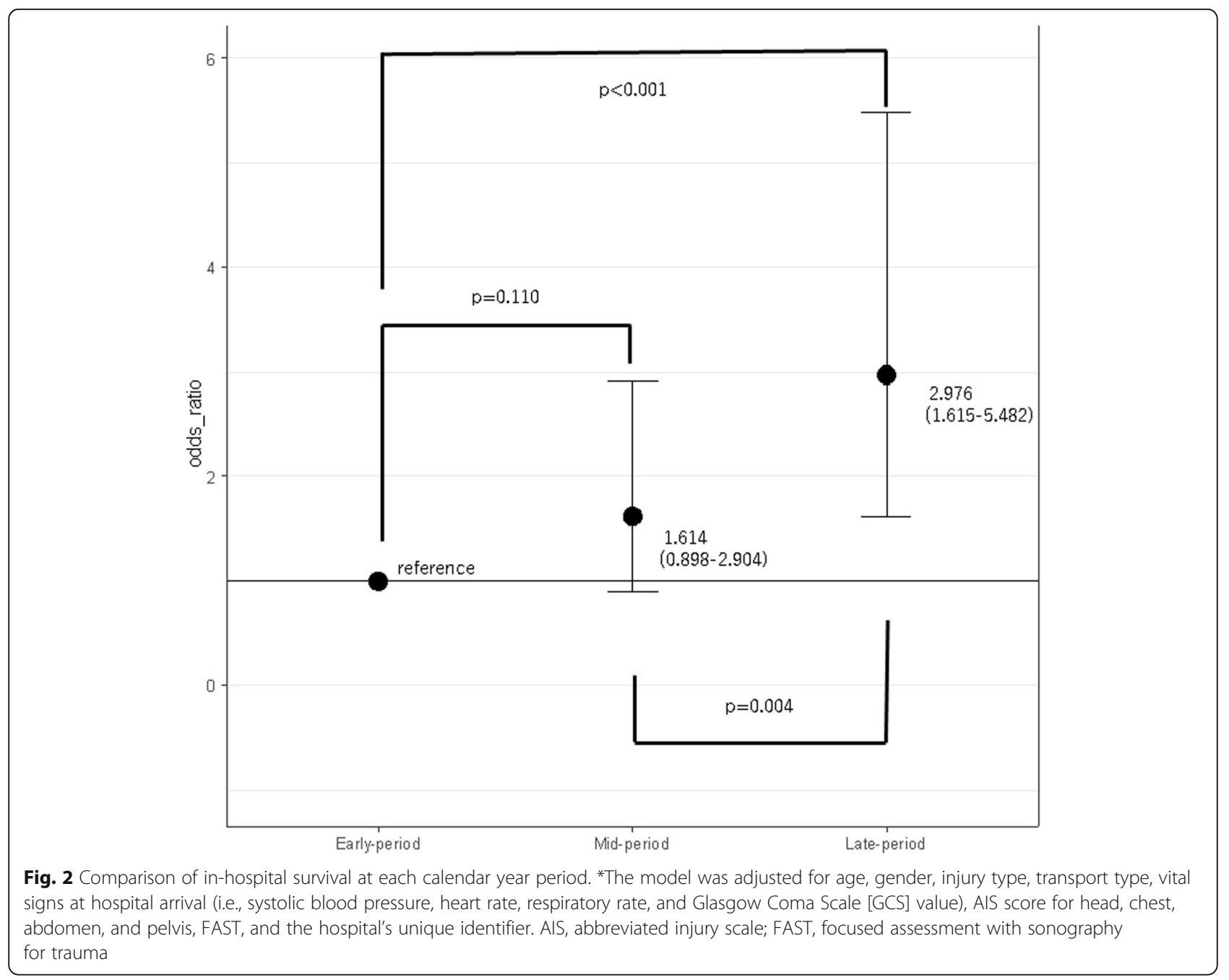




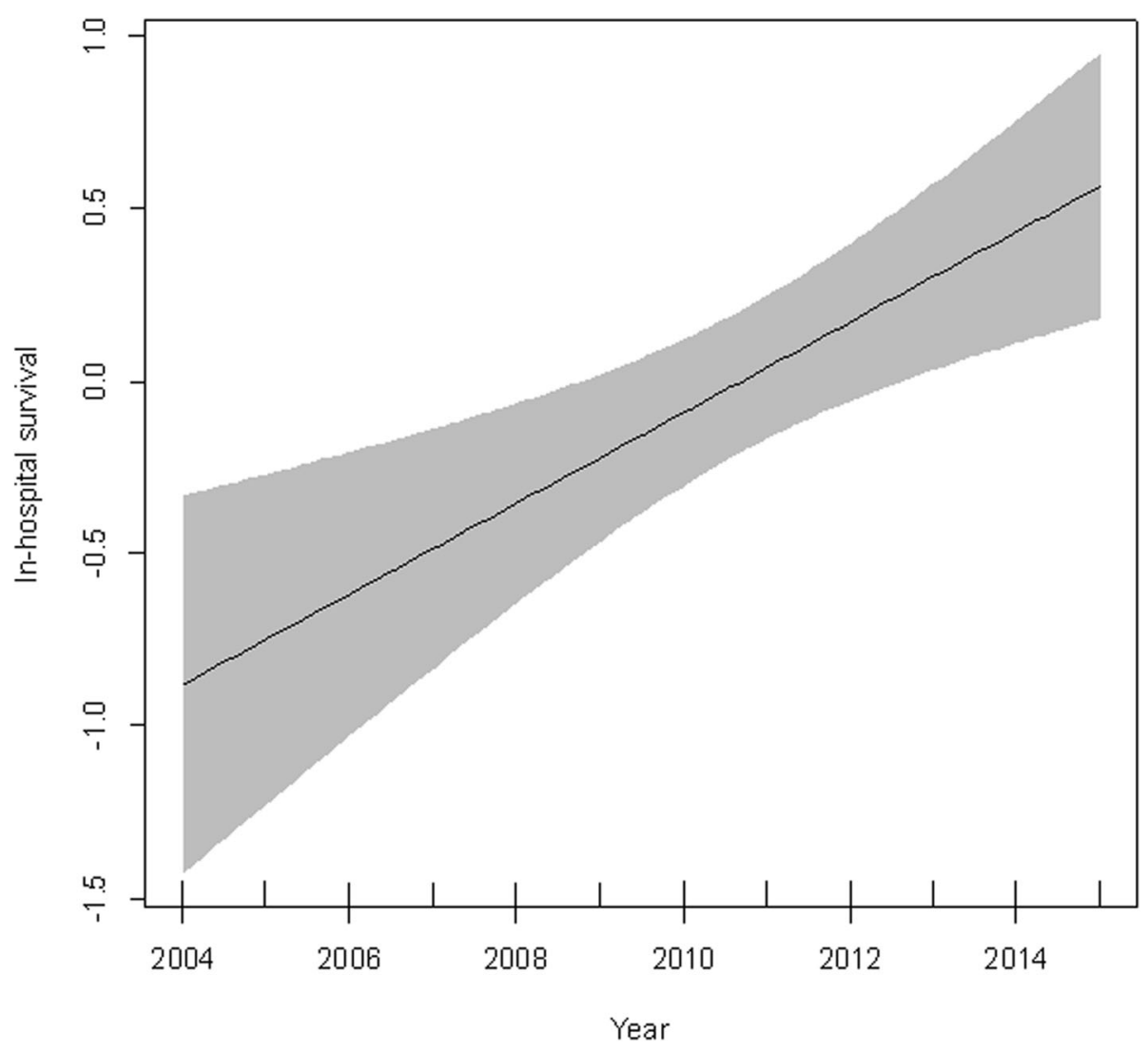

Fig. 3 Association between calendar year and in-hospital survival. The shaded region represents the 95\% confidence intervals for the estimated points. The model was adjusted for age, gender, injury type, transport type, vital signs at hospital arrival (i.e., systolic blood pressure, heart rate, respiratory rate, and Glasgow Coma Scale [GCS] value), AIS score for head, chest, abdomen, and pelvis, FAST, and the hospital's unique identifier. AIS, abbreviated injury scale; FAST, focused assessment with sonography for trauma

This study adds information about clinical treatment changes associated with the implementation of REBOA in Japan. REBOA was introduced in Japan in the early 2000s and its use has spread widely because the technique of endovascular therapy could match to emergency department physicians in Japan who had not enough experience of thoracotomy. As a result, clinicians selected transcatheter arterial embolization (TAE) following REBOA as endovascular therapy. The selection of TAE was supported by dissemination of non-operative management, and the combination of TAE and REBOA could have contributed to improved survival [31,32].

\section{Limitations}

Our study has several limitations. First, because of the nature of the JTDB database, some clinically important information was not registered. For example, the JTDB had no information about plasma quantity. Use of the high ratio massive transfusion protocol is one area of progress in modern trauma care [33]. Besides, JTDB did not have information about tranexamic acid use. These confounders were thought to be also contributing the improved survival in this study. Second, some important variables had missingness to some degree, and missingness could affect the results of this study. Prehospital vital signs were thought to be related to the indication for REBOA, therefore, we used a multiple imputation method. Although our methodology in handling missing data was considered reasonable and statistically appropriate, the results should be interpreted with caution because of the missing data. Third, important limitation as to REBOA. JTDB had no information of indication of REBOA, REBOA balloon size, initiation of REBOA time, how to use of REBOA (partial or not), and or so. During the study periods, physicians skills of using REBOA and REBOA devices were also improved, these were important factors associated with improved survival.

\section{Conclusions}

Survival of patients who were treated with REBOA during the late-period was improved compared with survival during the early-period, after adjustment for confounders. REBOA may be one of the important factors related to progression of modern trauma treatment. 


\section{Supplementary information}

Supplementary information accompanies this paper at https://doi.org/10. 1186/s13049-020-00757-2.

Additional file 1: Table S1. Baseline characteristics and proportion of missing data in naïve dataset.

Additional file 2: Table S2. Subgroups' and matched patients'

outcome according to year groups.

Additional file 3: Table S3. Survival of REBOA patients according to calendar year.

Additional file 4: Table S4. Survival of REBOA patients who had CPR according to calendar year.

Additional file 5: Table S5. Summary of previous studies about survival of REBOA patients.

Additional file 6: Table S6. Characteristics of matched patients with and without REBOA.

\section{Abbreviations}

REBOA: Resuscitative endovascular balloon occlusion of the aorta; JTDB: Japan Trauma Data Bank; AIS: Abbreviated injury scale; ISS: Injury severity score; RTS: Revised trauma score; Ps: Probability of survival; CPR: Cardiopulmonary resuscitation; IQR: Interquartile range; VIF: Variance inflation factor; GCS: Glasgow coma scale; FAST: Focused assessment with sonography for trauma; $\mathrm{Cl}$ : Confidence interval; OR: Odds ratio

\section{Acknowledgements}

We also thank the Japan Trauma Data Bank and all personnel at the participating institutions who contributed the data.

\section{Authors' contributions}

M.A. and T.A. designed this study. M.A. and T.A. contributed to the data collection, performed the data analyses, interpreted the data, and wrote the manuscript. M.A., T. A, D.S., and K. O. critically revised the final manuscript. The author(s) read and approved the final manuscript.

\section{Funding}

No funding.

\section{Availability of data and materials}

The datasets generated during and/or analyzed during the current study are available from the corresponding author on reasonable request.

\section{Ethics approval and consent to participate}

The study protocol was reviewed and approved by the Institutional Review Board of Gunma University Hospital. Given the retrospective and anonymized nature of this study, the Ethics Committees waived the need for informed consent from the study participants.

\section{Consent for publication}

Not applicable.

\section{Competing interests}

The authors declare that they have no competing interests.

\section{Author details}

'Department of Emergency Medicine, Gunma University Graduate School of Medicine, Maebashi, Japan. ${ }^{2}$ Department of General Medicine, Juntendo University, Tokyo, Japan. ${ }^{3}$ Health Services Research and Development Center, University of Tsukuba, Tsukuba, Japan. ${ }^{4}$ Department of Emergency Medicine, National Hospital Organization Takasaki General Medical Center, Takasaki, Japan. ${ }^{5}$ Department of Traumatology and Emergency Medicine, National Defense Medical College, Tokorozawa, Japan.
Received: 14 November 2019 Accepted: 24 June 2020

Published online: 30 June 2020

\section{References}

1. Hughes CW. Use of an intra-aortic balloon catheter tamponade for controlling intra-abdominal hemorrhage in man. Surgery. 1854;36(1):65-8.

2. Assar AN, Zarins CK. Endovascular proximal control of ruptured abdominal aortic aneurysms: the internal aortic clamp. J Cardiovasc Surg. 2009;50(3): $381-5$.

3. Ordonez CA, Manzano-Nunez R, Parra MW, Rasmussen TE, Nieto AJ, HerreraEscobar JP, Fernandez P, Naranjo MP, García AF, Carvajal JA, et al. Prophylactic use of resuscitative endovascular balloon occlusion of the aorta in women with abnormal placentation: a systematic review, metaanalysis, and case series. J Trauma Acute Care Surg. 2018;84(5):809-18.

4. Pieper A, Thony F, Brun J, Rodiere M, Boussat B, Arvieux C, Tonetti J, Payen $J F$, Bouzat P. Resuscitative endovascular balloon occlusion of the aorta for pelvic blunt trauma and life-threatening hemorrhage: a 20-year experience in a level I trauma center. J Trauma Acute Care Surg. 2018;84(3):449-53.

5. Ordonez CA, Parra MW, Manzano-Nunez R, Herrera-Escobar JP, Serna JJ, Rodriguez Ossa P, Mejia D, Del Valle AM, Salcedo A, Salamea JC, et al. Intraoperative combination of resuscitative endovascular balloon occlusion of the aorta and a median sternotomy in hemodynamically unstable patients with penetrating chest trauma: is this feasible? J Trauma Acute Care Surg. 2018:84(5):752-7.

6. Abe T, Uchida M, Nagata I, Saitoh D, Tamiya N. Resuscitative endovascular balloon occlusion of the aorta versus aortic cross clamping among patients with critical trauma: a nationwide cohort study in Japan. Crit Care. 2016; 20(1):400.

7. Norii T, Crandall C, Terasaka Y. Survival of severe blunt trauma patients treated with resuscitative endovascular balloon occlusion of the aorta compared with propensity score-adjusted untreated patients. J Trauma Acute Care Surg. 2015;78(4):721-8.

8. Joseph B, Zeeshan M, Sakran JV, Hamidi M, Kulvatunyou N, Khan M, O'Keeffe T, Rhee P. Nationwide analysis of resuscitative endovascula balloon occlusion of the aorta in civilian trauma. JAMA Surg. 2019. https:// doi.org/10.1001/jamasurg.2019.0096

9. Dubose JJ, Scalea TM, Brenner M, Skiada D, Inaba K, Cannon J, Moore L Holcomb J, Turay D, Arbabi CN, et al. AAST AORTA study group. The AAST prospective aortic occlusion for resuscitation in trauma and acute care surgery (AORTA) registry: data on contemporary utilization and outcomes of aortic occlusion and resuscitative balloon occlusion of the aorta (REBOA). J Trauma Acute Care Surg. 2016:81(3):409-19.

10. Hondo K, Shiraishi A, Fujie S, Saitoh D, Otomo Y. In-hospital trauma mortality has decreased in Japan possibly due to trauma education. J Am Coll Surg. 2013;217(5):850-7.

11. Endo A, Shiraishi A, Matsui H, Hondo K, Otomo Y. Assessment of Progress in early trauma Care in Japan over the past decade: achievements and areas for future improvement. J Am Coll Surg. 2017:224(2):191-8.

12. Nagata I, Abe T, Uchida M, Saitoh D, Tamiya N. Ten-year inhospital mortality trends for patients with trauma in Japan: a multicentre observational study. BMJ Open. 2018;8(2):e018635.

13. Rubin DB. Multiple imputation for nonresponse in surveys. New York: John Wiley; 1987.

14. Lendrum R, Perkins Z, Chana M, Marsden M, Davenport R, Grier G, Sadek S, Davies $\mathrm{G}$. Pre-hospital resuscitative endovascular balloon occlusion of the aorta (REBOA) for exsanguinating pelvic haemorrhage. Resuscitation. 2019; 135:6-13.

15. Moore LJ, Brenner M, Kozar RA, Pasley J, Wade CE, Baraniuk MS, Scalea T, Holcomb JB. Implementation of resuscitative endovascular balloon occlusion of the aorta as an alternative to resuscitative thoracotomy for noncompressible truncal hemorrhage. J Trauma Acute Care Surg. 2015;79(4): 523-30.

16. Brenner M, Inaba K, Aiolfi A, Dubose J, Fabian T, Bee T, Holcomb JB, Moore L, Skarupa D, Scalea TM. AAST AORTA study group. Resuscitative endovascular balloon occlusion of the aorta and resuscitative thoracotomy in select patients with hemorrhagic shock: early results from the American Association for the Surgery of Trauma's aortic occlusion in resuscitation for trauma and acute care surgery registry. J Am Coll Surg. 2018:226(5):730-40.

17. Gupta BK, Khaneja SC, Flores L, Eastick L, Longmore W, Shaftan GW. The role of intra-aortic balloon occlusion in penetrating abdominal trauma. J Trauma. 1989:29(6):861-5. 
18. Martinelli T, Thony F, Declety P, Sengel C, Broux C, Tonetti J, Payen JF, Ferretti G. Intra-aortic balloon occlusion to salvage patients with life-threatening hemorrhagic shocks from pelvic fractures. J Trauma. 2010;68(4):942-8.

19. Brenner ML, Moore LJ, DuBose JJ, Tyson GH, McNutt MK, Albarado RP, Holcomb JB, Scalea TM, Rasmussen TE. A clinical series of resuscitative endovascular balloon occlusion of the aorta for hemorrhage control and resuscitation. J Trauma Acute Care Surg. 2013;75(3):506-11.

20. Saito N, Matsumoto H, Yagi T, Hara Y, Hayashida K, Motomura T, Mashiko K, lida $\mathrm{H}$, Yokota H, Wagatsuma Y. Evaluation of the safety and feasibility of resuscitative endovascular balloon occlusion of the aorta. J Trauma Acute Care Surg. 2015;78(5):897-903.

21. Inoue J, Shiraishi A, Yoshiyuki A, Haruta K, Matsui H, Otomo Y. Resuscitative endovascular balloon occlusion of the aorta might be dangerous in patients with severe torso trauma: a propensity score analysis. J Trauma Acute Care Surg. 2016;80(4):559-66.

22. Tsurukiri J, Akamine I, Sato T, Sakurai M, Okumura E, Moriya M, Yamanaka H, Ohta S. Resuscitative endovascular balloon occlusion of the aorta for uncontrolled haemorrahgic shock as an adjunct to haemostatic procedures in the acute care setting. Scand J Trauma Resusc Emerg Med. 2016;24:13.

23. Teeter WA, Matsumoto J, Idoguchi K, Kon Y, Orita T, Funabiki T, Brenner ML, Matsumura Y. Smaller introducer sheaths for REBOA may be associated with fewer complications. J Trauma Acute Care Surg. 2016;81(6):1039-45.

24. Moore $L$, Martin CD, Hanvin JA, Wade CE, Holcomb JB. Resuscitative endovascular balloon occlusion of the aorta for control of noncompressible truncal hemorrhage in the abdomen and pelvis. Am J Surg. 2016;212(6):1222-30.

25. Aso $\mathrm{S}$, Matsui H, Fushimi K, Yasunaga $\mathrm{H}$. Resuscitative endovascular balloon occlusion of the aorta or resuscitative thoracotomy with aortic clamping for noncompressible torso hemorrhage: a retrospective nationwide study. J Trauma Acute Care Surg. 2017;82(5):910-4

26. Sadeghi M, Nilsson KF, Larzon T, Pirouzram A, Toivola A, Skoog P, Idoguchi K, Kon Y, Ishida T, Matsumura Y, et al. The use of aortic balloon occlusion in traumatic shock: first report from the ABO trauma registry. Eur J Trauma Emerg Surg. 2018;44(4):491-501.

27. Brenner M, Teeter W, Hoehn M, Pasley J, Hu P, Yang S, Romagnoli A, Diaz J, Stein $D$, Scalea T. Use of resuscitative endovascular balloon occlusion of the aorta for proximal aortic control in patients with severe hemorrhage and arrest. JAMA Surg. 2018;153(2):130-5.

28. Sato R, Kuriyama A, Takaesu R, Miyamae N, Iwanaga W, Tokuda H, Umemura T. Resuscitative endovascular balloon occlusion of the aorta performed by emergency physicians for traumatic hemorrhagic shock: a case series from Japanese emergency rooms. Crit Care. 2018;22(1):103.

29. Abe T, Takahashi O, Saitoh D, Tokuda Y. Association between helicopter with physician versus ground emergency medical services and survival of adults with major trauma in Japan. Crit Care. 2014;18(4):R146.

30. Matsumura Y, Matsumoto J, Kondo H, Idoguchi K, Funabiki T. DIRECT-IABO investigators. Partial occlusion, conversion from thoracotomy, undelayed but shorter occlusion: resuscitative endovascular balloon occlusion of the aorta strategy in Japan. Eur J Emerg Med. 2018;25(5):348-54.

31. Ogura T, Lefor AT, Nakano M, Izawa Y, Morita H. Nonoperative management of hemodynamically unstable abdominal trauma patients with angioembolization and resuscitative endovascular balloon occlusion of the aorta. J Trauma Acute Care Surg. 2015;78(1):132-5.

32. Aoki M, Hagiwara S, Miyazaki M, Kaneko M, Murata M, Nakajima J, Ohyama Y, Tamura J, Tsushima Y. Genuine splenic artery aneurysm rupture treated by N-butyl cyanoacrylate and metallic coils under resuscitative endovascular balloon occlusion of the aorta. Acute Med Surg. 2016;3(3):286-9.

33. King ER. Initial Care of the Severely Injured Patient. N Engl J Med. 2019; 380(8):763-70.

\section{Publisher's Note}

Springer Nature remains neutral with regard to jurisdictional claims in published maps and institutional affiliations.

Ready to submit your research? Choose BMC and benefit from:

- fast, convenient online submission

- thorough peer review by experienced researchers in your field

- rapid publication on acceptance

- support for research data, including large and complex data types

- gold Open Access which fosters wider collaboration and increased citations

- maximum visibility for your research: over $100 \mathrm{M}$ website views per year

At BMC, research is always in progress.

Learn more biomedcentral.com/submissions 